Research Article

\title{
Study on the Mechanical Characteristics of Surrounding Rock in Excavation
}

\author{
Xiaoqian Zhang $\mathbb{D}$, Chengwu Li, and Chengmin Wei \\ School of Emergency Management and Safety Engineering, China University of Mining and Technology (Beijing), \\ Beijing 100083, China \\ Correspondence should be addressed to Xiaoqian Zhang; sdslcszxq@163.com
}

Received 30 January 2021; Revised 14 February 2021; Accepted 18 February 2021; Published 26 February 2021

Academic Editor: Gan Feng

Copyright ( $) 2021$ Xiaoqian Zhang et al. This is an open access article distributed under the Creative Commons Attribution License, which permits unrestricted use, distribution, and reproduction in any medium, provided the original work is properly cited.

\begin{abstract}
Mine disasters, as associated problems in the development of coal resources, always threaten the life safety of miners and the production safety of enterprises. In coal roadway excavation, the coal in front of the excavation face is in a state of concentrated stress and the deformation is serious. The instability of the coal seam under stress is an important cause of the occurrence of coal and gas outburst. Thus, knowing the mechanical characteristics of surrounding rock in front of the working face is of great significance for deep understanding and effective prevention and control of coal-rock dynamic disasters. By analyzing the characteristics of stress evolution and deformation and failure in front of the heading face, the analytical solution of plastic region distribution in front of the heading face is obtained. According to the established mechanical model, MATLAB numerical calculation software is used to analyze different examples. The influence of different mechanical parameters on the stress state of the working face is studied. The influence parameters of the morphological characteristics of the plastic region are determined, and the change law and characteristics of the plastic region in front of the working face are studied. At the same time, through the characteristics of stress field, the working face dynamic risk assessment of coal and rock dynamic disaster can be realized, which can provide a powerful guarantee for the prevention and control of gas dynamic disasters in deep mine.
\end{abstract}

\section{Introduction}

From 2006 to 2019 , a total of 10,278 accidents occurred in coal mines in China, resulting in 29,312 deaths. As shown in Figure 1, various disasters and accidents have seriously affected the safe production of coal mine enterprises. It can be seen from Figure 1 that in recent years, the number of accidents and death tolls have shown a downward trend, and China has achieved remarkable fruits in coal production safety. Among all kinds of accidents, the number of roof accidents is nearly twice that of gas accidents, while the death toll of gas accidents is more than twice that of roof accidents, which is close to the sum of the death tolls of the other five types of accidents. Therefore, the gas accident is the biggest threat to the life safety of miners. Thus, the prevention of gas disasters is the focus of mine safety work, and it is also a key scientific issue in research studies on gas mine. Coal and gas outburst accidents mainly occur in the driving face of coal roadway; in essence, it is a process of coal-rock mass instability under mining disturbance, and the redistribution of stress in front of the working face caused by mining operation is the source of this accident and its evolution. Mining operation breaks the original stress balance state in front of the working face and causes stress redistribution. And the stress redistribution changes the environment of coal-rock mass, which causes a large number of fractures in coal-rock mass, so a mining-induced fracture field is formed, and a mass of interconnecting fractures provides good channels for gas migration. When the peak stress exceeds the strength of the rock mass, the elastic energy and gas pressure accumulated in front of the working face are suddenly released, resulting in gas outburst. Therefore, studying the mechanical characteristics of surrounding rock in front of the excavation is of great significance to the accuracy of coal and gas outburst prediction. 


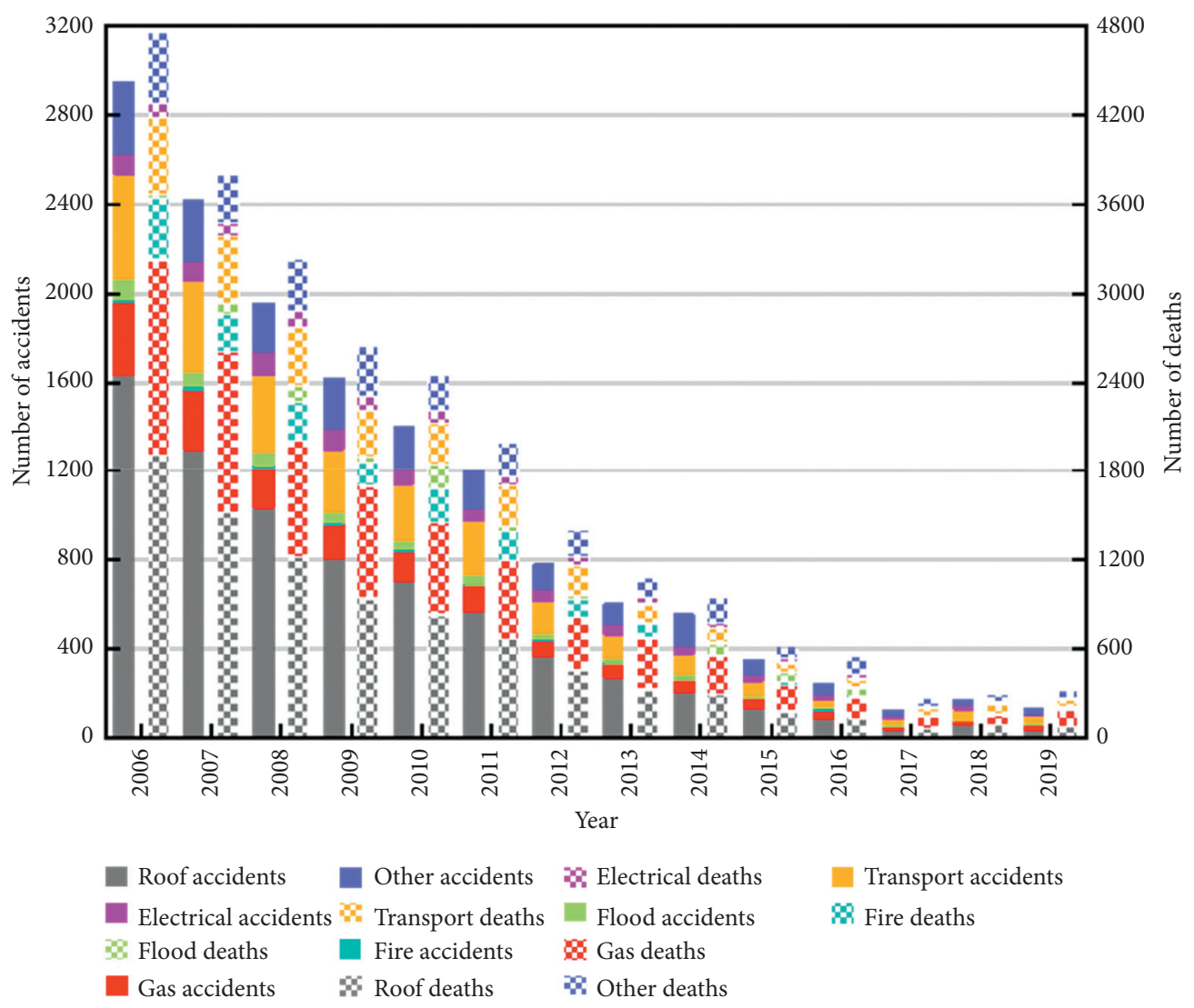

Figure 1: The number of accidents and the number of deaths in coal mines.

Coal and gas outburst is one of the most serious disasters in coal mines all over the world. In order to better explain the mechanical mechanism and physical process of sudden failure of coal and rock mass at the moment of coal and gas outburst, Li et al. [1] studied the rockburst phenomenon caused by tunnel excavation through physical simulation test under twodimensional stress and high in situ stress conditions and physical simulation study of similar material for rockburst and the failure characteristics of tunnel as rockburst under high in situ stress conditions; their test results indicated that tensile rockburst mainly occurs in tunnels with the patterns of spalling, buckling, and cracking. Based on the in situ stress measurement data from Xinwen Mining Area, Kang [2] analyzed the differences on stress state and ratio of horizontal stress to vertical stress between shallow and deep coal mines and figured out the distribution scope, peak value, and spatial relation with the working face of mining-induced stresses through analysis on the monitoring data. Liu et al. [3] proposed a real-time stress monitoring system to measure the mininginduced stress field in No. 2 Coal Mine of Pingdingshan Tianan Coal Co. Ltd. and studied the distribution and variation of stress along strike and inclination; their results showed that in the upper part of the working face, which is approaching the gob side, the influencing distance of advanced mining-induced stress, the stress concentration range within the roadway coal sidewalls is larger, the stress concentration factor and peak value of stress are higher, and the stress distribution and variation are quite different between the head and end of the working face. Wang et al. [4] studied the distribution characteristics of the working face in mining stress field under the fault existing conditions by means of similar simulation. $\mathrm{Xu}$ [5] built a coupling mechanism model of a stressometer and coalrock mass surrounding the drill hole and developed a mining stress monitoring system and applied it on the spot. Based on the surrounding rock stress shell theory, Zhang [6] carried out research such as numerical and physical modeling tests and case analysis to investigate the coal pillar width effect on the evolution characteristics of the surrounding rock stress field, damage field, and displacement field in asymmetric mining. In addition, Kang [7] classified the stress fields in underground coal mines, put forward the concept of supporting stress fields, and analyzed the interaction and relation between mining and supporting stress fields. Luan et al. [8] studied the mining stress field by the method of numerical simulation and field measurement; their results indicated that the abutment pressure field in front of the coal wall is not distributed symmetrically along the middle of the working face. Lu [9] found that mining stress presented different dynamic laws at different driving speeds, and the mining speed had a great impact on the distribution of dynamic stress. Xu [10] obtained the calculation formula of floor stress and deformation and damage judgment basis through theoretical analysis and numerical simulation. Burra et al. [11] studied the stress fluctuation and anisotropy of effective horizontal stress in coalbed methane area of Sydney. Zhang et al. [12] studied the failure laws and characteristics of coal and rock mass with the theory of "strong and soft face" and 
obtained the distribution range of plastic region in front of working face. Najafi et al. [13] studied the characteristics of stress thermal coupling effect in underground coal gasification area. Dong [14] researched Xuandong Second Mine's stope stress distribution discipline and its gas migration characteristic by field data. Hu and Xie [15] conducted intensive study of coupling characteristics of coal seam gas pressure and mininginduced stress in the working face; their results showed that the coal mechanical state in the working face is fundamental to the difference of coupling gas pressure and mining-induced stress of coal seam, and the peak position will assume asynchronous features between gas pressure and mining-induced stress of coal seam in the working face when dilatancy happens. Guo [16] studied the crack propagation and gas migration law caused by the change of multicoal mining stress. Somerton et al. [17] studied the influence of stress on coal permeability. Durucan and Edwards [18] experimentally analyzed the influence of stress and failure on coal permeability, while Jasinge et al. [19] studied the effect of effective stress on the permeability of lignite specimens. Palmer [20] theoretically analyzed the mechanism of coal permeability change under stress and gave a mathematical model of coal permeability change. Liu et al. [21] passed the modulus under directional strain conditions. The reduction rate of elastic modulus was used to calculate the directional permeability of coal. Zhang et al. [22] studied the influence of matrix deformation caused by adsorption on coal seam gas flow and gave a new finite element solution model. Meng et al. [23-25] studied the mechanical properties of soil-rock mixtures (SRMs) and modified the modeling method for simulating SRM deformation behavior. Zhu et al. [26-28] analyzed the influence of load and rainfall on the stability of deep foundation pit and studied the problem of non-Darcy flow in fractured medium by an experimental method. Meanwhile, for the mechanical model of coal and the characteristics of pressure distribution, Wang et al. [29] established the mechanical model of the stress distribution in front of the heading face and simulated the stress by using 3DEC numerical simulation software. Taking Ganhe Coal Mine as the engineering background, Wu et al. [30] analyzed the mechanical model of silo wall and carried out dynamic analysis. Ning et al. [31] studied the mechanical mechanism and development of overlying rock fragmentation in fracture zone in coal seam group mining. Yu et al. [32] deduced the mechanical model of continuous failure of top coal based on damage mechanics and statistical strength theory.

In summary, scholars at home and abroad have conducted extensive studies on dynamic failure characteristics of coal-rock mass in front of the driving face $[33,34]$. However, its complicated mechanism often causes the failure of conventional prevention and control techniques. Moreover, the research studies on the stress state of coal-rock mass and form of the plastic region are still relatively scarce. Consequently, it is still necessary to carry out studies on the dynamic response law of coalrock mass in front of the working face along with the tunneling operation based on the above work. This work will help improve the monitoring and early warning of coal and rock dynamic disasters and promote coal mine safety production.

\section{Mechanical Model}

Before the excavation of the roadway, the coal and rock mass is usually in an elastic equilibrium state. The roadway excavation breaks the equilibrium state, the original rock stress is redistributed, the tangential stress in front of the working face increases, the radial stress decreases, and the stress concentration phenomenon occurs. At this time, the stress of the surrounding rock in the front of the working face is greater than the strength of the rock mass, and plastic deformation occurs in the front of the working face. As the distance from the working face gets farther and farther, the stress of the surrounding rock is continuously reduced, and finally it becomes less than the strength of the rock mass. At this time, the surrounding rock is in an elastic state, as shown in Figure 2. Therefore, the redistribution of stress changes the surrounding rock from a state of high stress field to a state of low confining pressure and high stress difference, so the roadway tunneling is an unloading process. The reduction of confining pressure and redistribution of stress cause deformation of surrounding rock, which reduces the rock mass strength and elastic modulus. Moreover, as the deformation degree of surrounding rock increases and the stress increases, the strength of coal and rock mass becomes smaller and smaller, and the plastic region of coal and rock mass in front of working face becomes larger and larger, and it advances to the deep part of rock mass. Based on elasticity, this paper studies the law of stress variation of coal and rock mass in front of the heading face, and then the distribution range and characteristics of the plastic region in front of the working face are calculated by combining Mohr's theory of failure and boundary equation of elasto-plastic boundary, analytical solution of the stress distribution in front of the work surface, and the radius of the plastic region are obtained.

2.1. Distribution Characteristics of Stress Fields. It is assumed that the depth of the tunnel is much larger than the radius of the tunnel, and that the coal and rock mass are isotropic homogeneous media. We apply theories of elastoplastic mechanics and damage mechanics when the stress state is simplified to the plane stress state. We obtain the calculation formula of the stress field of the tunnel under the condition of bidirectional unequal pressure stress field:

$$
\left\{\begin{array}{l}
\sigma_{r}=\frac{1}{2} P_{0}(1+\lambda)\left(1-\frac{R_{0}^{2}}{r^{2}}\right)-\frac{1}{2} P_{0}(1-\lambda)\left(1-4 \frac{R_{0}^{2}}{r^{2}}+3 \frac{R_{0}^{4}}{r^{4}}\right) \cos 2 \theta \\
\sigma_{\theta}=\frac{1}{2} P_{0}(1+\lambda)\left(1+\frac{R_{0}^{2}}{r^{2}}\right)+\frac{1}{2} P_{0}(1-\lambda)\left(1+3 \frac{R_{0}^{4}}{r^{4}}\right) \cos 2 \theta \\
\tau_{r \theta}=\frac{1}{2} P_{0}(1-\lambda)\left(1+2 \frac{R_{0}^{2}}{r^{2}}-3 \frac{R_{0}^{4}}{r^{4}}\right) \sin 2 \theta \\
\sigma_{z}=\mu\left(\sigma_{r}+\sigma_{\theta}\right)
\end{array}\right.
$$

Internal stress in the plastic region refers to the ultimate stress that the fractured rock can bear. It has little relation to 


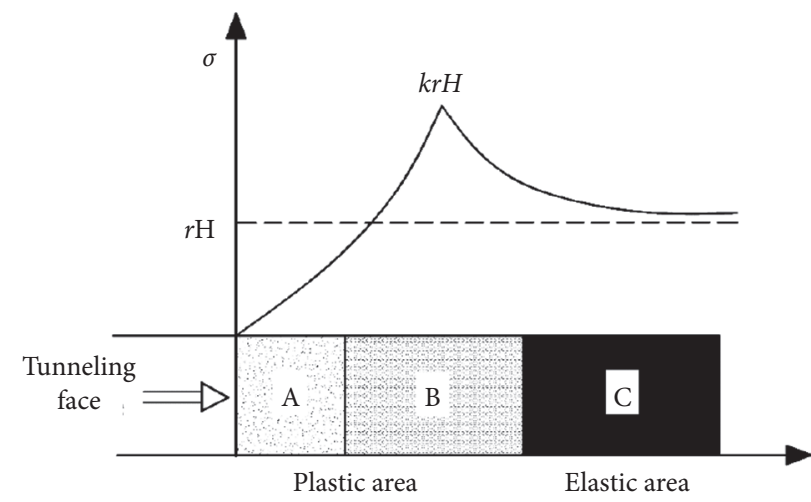

Figure 2: Schematic diagram of regional distribution of mining stress field [12].

original rock stress. And the stress state of the plastic region in front of the heading face is more consistent with the limit equilibrium equation. Due to the symmetrical and circular roadway, the internal stress in the fracture region can be approximated as axisymmetric. Thus, the internal stress in the fracture region is the same as the stress under equal pressure:

$$
\left\{\begin{array}{l}
\sigma_{r p}=\operatorname{Kctg} \varphi\left[\left(\frac{r}{R_{0}}\right)^{2 \sin \varphi / 1-\sin \varphi}-1\right], \\
\sigma_{\theta p}=\operatorname{Kctg} \varphi\left[\frac{1+\sin \varphi}{1-\sin \varphi}\left(\frac{r}{R_{0}}\right)^{2 \sin \varphi / 1-\sin \varphi}-1\right] .
\end{array}\right.
$$

External stress in the fracture region belongs to an elastic stress state; however, when $r=R_{0}$, the rock mass presents a fracture state, so the stress formula should be changed

$$
\left\{\begin{array}{l}
\sigma_{r}=\frac{1}{2} P_{0}(1+\lambda)\left(1-\frac{b}{r^{2}}\right)-\frac{1}{2} P_{0}(1-\lambda)\left(1-\frac{2 c}{r^{2}}+\frac{d}{r^{4}}\right) \cos 2 \theta, \\
\sigma_{\theta}=\frac{1}{2} P_{0}(1+\lambda)\left(1+\frac{b}{r^{2}}\right)+\frac{1}{2} P_{0}(1-\lambda)\left(1+\frac{d}{r^{4}}\right) \cos 2 \theta, \\
\tau_{r \theta}=\frac{1}{2} P_{0}(1-\lambda)\left(1+\frac{c}{r^{2}}-\frac{d}{r^{4}}\right) \sin 2 \theta .
\end{array}\right.
$$

In this formula, when $r=R_{p}, \sigma_{r p}=\sigma_{r t}, \sigma_{\theta p}=\sigma_{\theta t}$, $\tau_{r \theta t}=\sigma_{r \theta p}=0$, that is, internal stress in the fracture region is equal to external stress in it, and the constants $b, c$, and $d$ can be obtained by using stress continuity condition. Since original rock stress is not axisymmetric, the radius of the fracture region is also asymmetric and the radius of the fracture region is a function of $\theta$. In this paper, the radius of the fracture region can be regarded as two parts: one is $\theta$ independent of $r_{p}$ and the other one is related to $\theta$; therefore, the radius of the fracture region $R_{p}$ can be written as

$$
R_{p}=r_{p}+\frac{1-\lambda}{2} f(\theta)=r_{p}\left[1+\frac{1-\lambda}{2 r_{p}} f(\theta)\right] \text {. }
$$

Substituting equation (4) into equation (3), the expression of internal stress in the fracture region becomes

$$
\left\{\begin{array}{l}
\sigma_{r p}=\operatorname{Kctg} \varphi\left(\frac{r_{p}}{R_{0}}\right)^{a}+\frac{a(1-\lambda)}{2 r_{p}} \operatorname{Kctg} \varphi\left(\frac{r_{p}}{R_{0}}\right)^{a} f(\theta)-K c t g \varphi, \\
\sigma_{\theta p}=(a+1) \operatorname{Kctg} \varphi\left(\frac{r_{p}}{R_{0}}\right)^{a}+\frac{a(a+1)(1-\lambda)}{2 r_{p}} \operatorname{Kctg} \varphi\left(\frac{r_{p}}{R_{0}}\right)^{a} f(\theta)-K c t g \varphi, \\
\tau_{r \theta}=0 .
\end{array}\right.
$$


The expression of external stress in the fracture region becomes

$$
\left\{\begin{array}{l}
\sigma_{r}=\frac{1}{2} P_{0}(1+\lambda)\left(1-\frac{b}{r_{p}^{2}}\right)+\frac{1}{2} P_{0}(1+\lambda) \frac{b_{0}(1-\lambda)}{r_{p}^{3}} f(\theta)-\frac{1}{2} P_{0}(1-\lambda)\left(1-\frac{2 c}{r_{p}^{2}}+\frac{d}{r_{p}^{4}}\right) \cos 2 \theta, \\
\sigma_{\theta}=\frac{1}{2} P_{0}(1+\lambda)\left(1+\frac{b}{r_{p}^{2}}\right)-\frac{1}{2} P_{0}(1+\lambda)\left(1+\frac{b(1-\lambda)}{r_{p}^{3}}\right) f(\theta)+\frac{1}{2} P_{0}(1-\lambda)\left(1+\frac{d}{r_{p}^{4}}\right) \cos 2 \theta, \\
\tau_{r \theta}=\frac{1}{2} P_{0}(1-\lambda)\left(1+\frac{c}{r^{2}}-\frac{d}{r^{4}}\right) \sin 2 \theta .
\end{array}\right.
$$

In this expression, constants $a, b$, and $c$ can be obtained by solving the equations simultaneously with boundary conditions.
Substituting equation (6) into stress value of the plastic region and elastic region, the stress of $r=R_{p}$ at the transition points of the plastic region and elastic region can be obtained:

$$
\left\{\begin{array}{l}
\sigma_{r p}=K c t g\left(\frac{r_{p}}{R_{0}}\right)^{a}+\frac{a(1-\lambda)}{2 r_{p}} K c t g\left(\frac{r_{p}}{R_{0}}\right)^{a} f(\theta)-K c t g \phi, \\
\sigma_{\theta p}=(a+1) K c t g\left(\frac{r_{p}}{R_{0}}\right)^{a}+\frac{a(a+1)(1-\lambda)}{2 r_{p}} \operatorname{Kctg}\left(\frac{r_{p}}{R_{0}}\right)^{a} f(\theta)-K c t g \phi, \\
\sigma_{r t}=\frac{1}{2} P_{0}(1+\lambda)\left(1-\frac{b}{r_{p}^{2}}\right)+\frac{1}{2} P_{0}(1+\lambda)\left(\frac{b(1-\lambda)}{r_{p}^{3}}\right) f(\theta)-\frac{1}{2} P_{0}(1-\lambda)\left(1-\frac{2 c}{r_{p}^{2}}+\frac{d}{r_{p}^{4}}\right) \cos 2 \theta, \\
\sigma_{\theta t}=\frac{1}{2} P_{0}(1+\lambda)\left(1+\frac{b}{r_{p}^{2}}\right)-\frac{1}{2} P_{0}(1+\lambda)\left(\frac{b(1-\lambda)}{r_{p}^{3}}\right) f(\theta)+\frac{1}{2} P_{0}(1+\lambda)\left(1+\frac{d}{r_{p}^{4}}\right) \cos 2 \theta, \\
\tau_{r \theta t}=\frac{1}{2} P_{0}(1-\lambda)\left(1+\frac{c}{r_{p}^{2}}-\frac{d}{r_{p}^{4}}\right) \sin 2 \theta .
\end{array}\right.
$$


As $r=R_{p}, \sigma_{r p}=\sigma_{r t}, \sigma_{\theta p}=\sigma_{\theta t}, \tau_{\theta p}=\tau_{\theta t}$, the three terms independent of $\theta$ are equal to those related to $\theta$.

$$
\left\{\begin{array}{l}
\operatorname{Kctg} \varphi\left(\frac{r_{p}}{R_{p}}\right)^{a}-k \operatorname{ctg} \varphi=\frac{1}{2} P_{0}(1+\lambda)\left(1-\frac{b}{r_{p}^{2}}\right), \\
\frac{a}{r_{p}} \operatorname{Kctg} \varphi\left(\frac{r_{p}}{R_{p}}\right)^{a} f(\theta)=\frac{P_{0} b(1+\lambda)}{r_{p}^{3}} f(\theta)-P_{0}\left(1-\frac{2 c}{r_{p}^{2}}+\frac{d}{r_{p}^{4}}\right) \cos 2 \theta, \\
(a+1) \operatorname{Kctg} \varphi\left(\frac{r_{p}}{R_{p}}\right)^{a}-K \operatorname{ctg} \varphi=\frac{1}{2} P_{0}(1+\lambda)\left(1+\frac{b}{r_{p}^{2}}\right), \\
\frac{a}{r_{p}} \operatorname{Kctg} \varphi\left(\frac{r_{p}}{R_{p}}\right)^{a} f(\theta)=\frac{-P_{0} b(1+\lambda)}{r_{p}^{3}} f(\theta)+P_{0}\left(1+\frac{d}{r_{p}^{2}}\right) \cos 2 \theta, \\
1+\frac{c}{r_{p}^{3}}-\frac{d}{r_{p}^{4}}=0 .
\end{array}\right.
$$

Combining these five equations, $r_{p}, b, c, d$, and $f(\theta)$ can be solved,

$$
\left\{\begin{array}{l}
r_{p}=R_{0}\left\{\frac{\left[P_{0}(1+\lambda)+2 K c \tan \varphi\right](1-\sin \varphi)}{2 K c \tan \varphi}\right\}^{1-\sin \varphi / 2 \sin \varphi}, \\
b=\frac{r_{p}^{2} \sin \varphi\left[P_{0}(1+\lambda)+2 K c \tan \varphi\right]}{P_{0}(1+\lambda)}, \\
c=2 r_{p}^{2}, \\
d=3 r_{p}^{2} .
\end{array}\right.
$$

Substituting $r_{p}, b, c$, and $d$ into the equation, the analytical formula of stress and expression of radius of the plastic region can be obtained:

$$
\left\{\begin{array}{l}
\sigma_{r}=\frac{1}{2} P_{0}(1+\lambda)-\frac{r_{p}^{2} \sin \varphi}{2 r^{2}}\left[P_{0}(1+\lambda)+2 K \operatorname{ctg} \varphi\right]-\frac{1}{2} P_{0}(1-\lambda)\left(1-4 \frac{r_{p}^{2}}{r^{2}}+3 \frac{r_{p}^{4}}{r^{4}}\right) \cos 2 \theta, \\
\sigma_{\theta}=\frac{1}{2} P_{0}(1+\lambda)+\frac{r_{p}^{2} \sin \varphi}{2 r^{2}}\left[P_{0}(1+\lambda)+2 K \operatorname{ctg} \varphi\right]+\frac{1}{2} P_{0}(1-\lambda)\left(1+3 \frac{r_{p}^{4}}{r^{4}}\right) \cos 2 \theta, \\
\tau_{r \theta}=\frac{1}{2} P_{0}(1-\lambda)\left(1+2 \frac{r_{p}^{2}}{r^{2}}-3 \frac{r_{p}^{4}}{r^{4}}\right) \sin 2 \theta \\
R_{p}=R_{0}\left\{\frac{\left[P_{0}(1+\lambda)+2 K \operatorname{ctg} \varphi\right](1-\sin \varphi)}{2 K c t g \varphi}\right\}^{1-\sin \varphi / 2 \sin \varphi}\left\{1+\frac{(1-\sin \varphi) P_{0}(1+\lambda) \cos 2 \theta}{\sin \varphi\left[P_{0}(1+\lambda)+2 K c t g \varphi\right]}\right\} .
\end{array}\right.
$$

\section{Numerical Simulation}

Using the analytical formula of stress distribution in front of the working face deduced above, the influence of lithology, cohesion, internal friction angle, etc. on the stress distribution in the driving face is analyzed.

\subsection{Relationship between Lithology and Stress Distribution.} Different coal-rock masses have different mechanical properties (such as strength, elastic modulus, internal friction angle, and so on). Deformation, failure, and instability of coal-rock masses are not only related to mining operation but also related to physical and mechanical properties. Thus, the influence of different coal and rock masses on the stress distribution of the working face is obtained according to the stress analytical formula above. We used equation (10) to study the influence of different coal-rock masses on stress distribution of the working face, as shown in Figure 3.

In Figure 3, the black curved line indicates that the roadway is a semicircular arch with a radius of $2 \mathrm{~m}$. The abscissa and ordinate represent the driving direction and driving size. The red, black, and blue curves represent the stress value in front of the working face. The left side of the peak is the plastic region, and the right side of the peak is the elastic region. As can be seen from Figure 1, the rock mass is of larger strength and hardness, so in the excavation process of rock roadway, the concentrated stress effect is the most obvious, with the highest stress peak and the greatest stress increment. Compared with rock mass, the coal mass is of smaller strength and stronger stability; for this reason, the coal mass is the most likely to crack and fracture under the influence of the same mining operation, and coal mass has the smallest concentrated stress peak, the largest plastic 


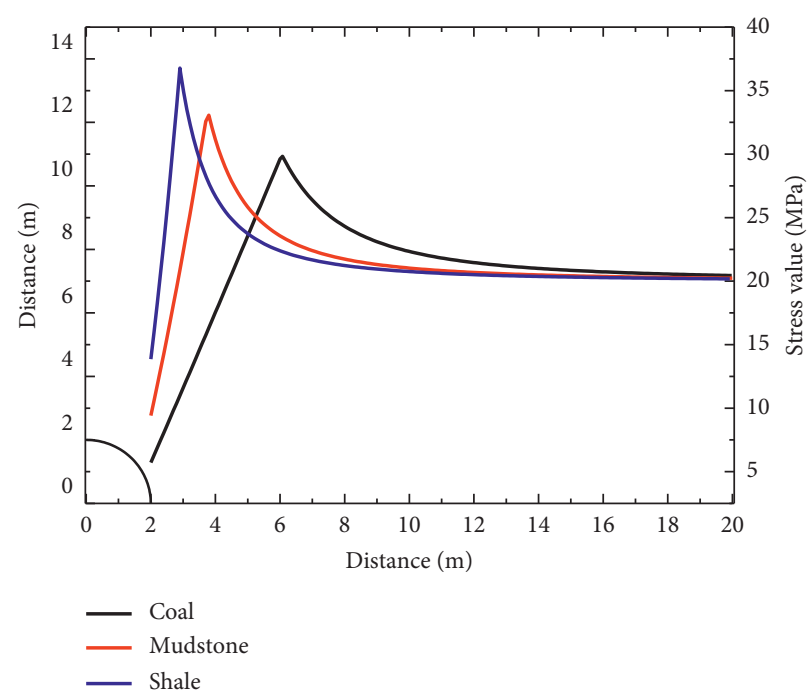

Figure 3: Relationship between lithology and original rock stress.

range, and the smallest elastic range. According to this figure, lithology has obvious influence on the stress distribution in front of the driving face.

\subsection{Relationship between Original Rock Stress and Stress} Distribution. Original rock stress refers to the pressure above the working face. We used equation (10) to study the influence of original rock stress on the stress state of the driving face as shown in Figure 4.

Original rock stress is related to mining depth; with the increase of mining depth, the confining pressure in deep and shallow part of coal-rock mass varies greatly. As shown in Figure 4, the width of the plastic region and concentrated stress value increase with the increase of original rock stress. When the original rock stress is $10 \mathrm{MPa}$, the concentrated stress occurs at a distance of $1 \mathrm{~m}$ from the working face, and the stress peak is only $15 \mathrm{MPa}$; in this case, deformation and failure are not easy to occur. When the original rock stress is $40 \mathrm{MPa}$, the concentrated stress occurs at a distance of $7 \mathrm{~m}$ from the working face, and the stress peak is $60 \mathrm{MPa}$. It can be seen that with the increase of mining depth, the variation of concentrated stress peak is greater than original rock stress; when the concentrated stress peak is greater than the yield limit of coal-rock mass, deformation, instability, and failure are easy to occur.

\subsection{Relationship between Internal Friction Angle (Cohesion)} and Stress Distribution. The internal friction angle reflects shear strength of coal-rock mass. The variation of the internal friction angle can induce the change of the form of bending section of coal mass. Thus, this paper used equation (10) to study the influence of the internal friction angle on stress distribution of the driving face (Figure 5). It shows the relationship between the internal friction angle of coal-rock mass and stress state in front of the driving face. The larger the internal friction angle, the smaller the plastic region and the larger the concentrated stress value. This indicates that the smaller the internal friction angle, the smaller the coal strength, the softer the coal mass, the smaller the compressive strength, and the larger the plastic region in front of the working face. Under the same original rock stress and mining operation, coal-rock mass with small internal friction angle is more prone to failure obviously, and the concentrated stress value is also smaller.

\section{Factors Affecting Distribution Form of the Plastic Region}

Width and distribution form of the plastic region are basic factors affecting the stability of surrounding rock in the working face. According to the stress distribution diagram, the front part of the stress peak is the plastic region and the back part of the stress peak is the elastic region; the width and geometric dimensions of the plastic region determine the failure state of coal-rock mass. If the plastic region is large and coal mass is broken seriously, coal and gas outburst are likely to occur. Based on the previous analysis, this section analyzed factors affecting width and form features of the plastic region and provided theoretical basis and design guidance for roadway design and mining operation by using the analytical formula for radius of the plastic region under unequal compression in two-direction stress field.

4.1. Influence of Original Rock Stress on Form Features of the Plastic Region. Deep mine construction is a new issue that coal engineering must face, and coal mines with depth more than $1000 \mathrm{~m}$ are becoming the norm. With the increase of surrounding rock stress and gas pressure in deep mine, the risk of coal and rock dynamic disaster in working face increases. Therefore, this paper uses the analytical formula of plastic region radius in Equation 8 to study the influence of original rock stress on the distribution characteristics of plastic region in front of working face. We assume that the 


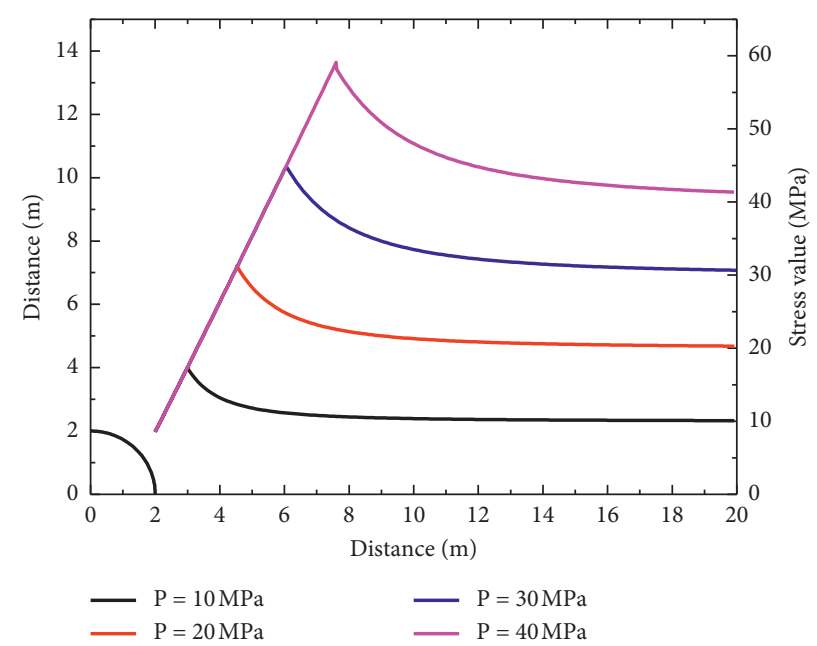

FIGURE 4: Relationship between original rock stress and stress distribution.

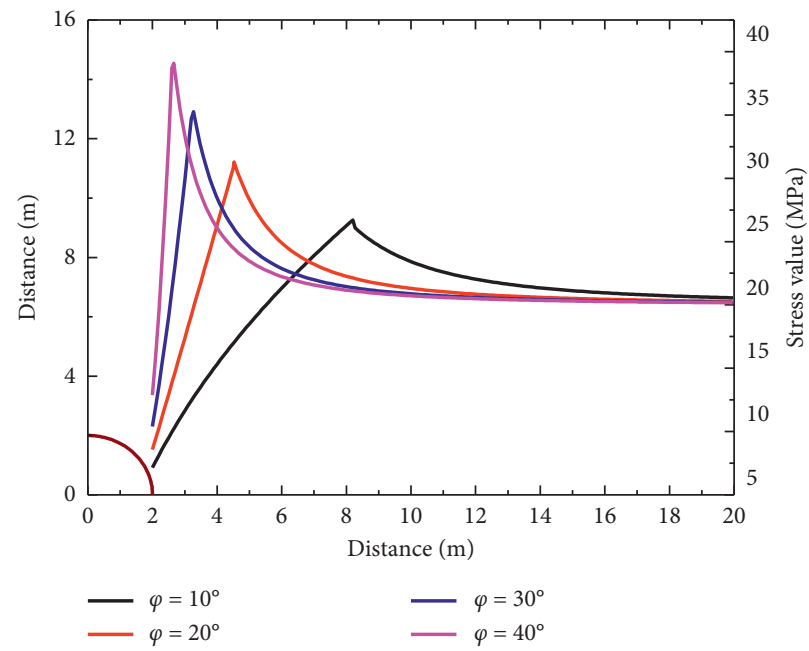

FIgURE 5: Relationship between the internal friction angle and stress distribution.

original rock stress increases from $10 \mathrm{MPa}$ to $40 \mathrm{MPa}$ and analyze the geometric size change rule of the plastic region of coal and rock mass in front of the working face. As can be seen from Figure 6, dimensions of every angle of the plastic region increase with the increase of original rock stress. The results show that as original rock stress increases from $10 \mathrm{MPa}$ to $40 \mathrm{MPa}$, geometric dimensions of the plastic region at all angles increase, the width of the plastic region in front of the working face increases from $2.94 \mathrm{~m}$ to $7.61 \mathrm{~m}$, and the vertical direction of the working face increases from $2.03 \mathrm{~m}$ to $4.08 \mathrm{~m}$.

When the lateral pressure coefficient is 0.5 , we used equation (10) to study the distribution characteristics of the plastic region with different original rock stress (Figure 6). From the points of distribution form of the plastic region, all plastic regions in front of the driving face are irregular, and with the increase of original rock stress, geometric dimensions of width of the plastic region increase significantly, and distribution forms of the plastic region are roughly the same. This shows that when the bidirection pressure ratio is constant, the distribution form of the plastic region is basically unchanged, and original rock stress only affects geometric dimension of the plastic region; it has little influence on the form of the plastic region.

\subsection{Influence of Internal Friction Angle on Form Features of the} Plastic Region. The internal friction angle also has an important influence on the form of the plastic region. We use equation (10) to study the width of the plastic region which decreases with the increase of the internal friction angle (Figure 7). 


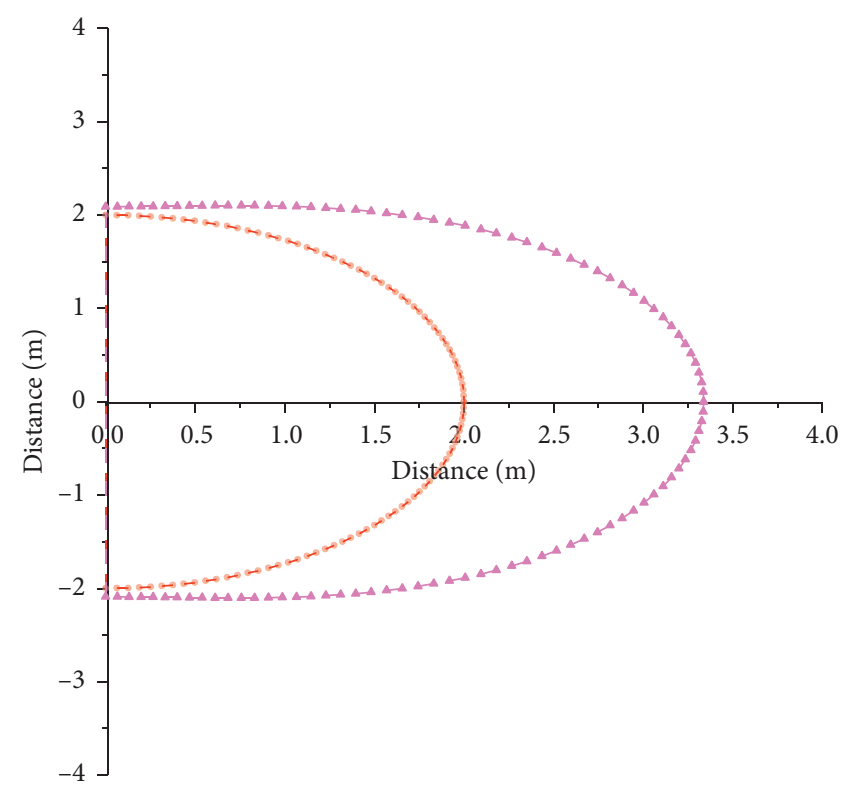

(a)

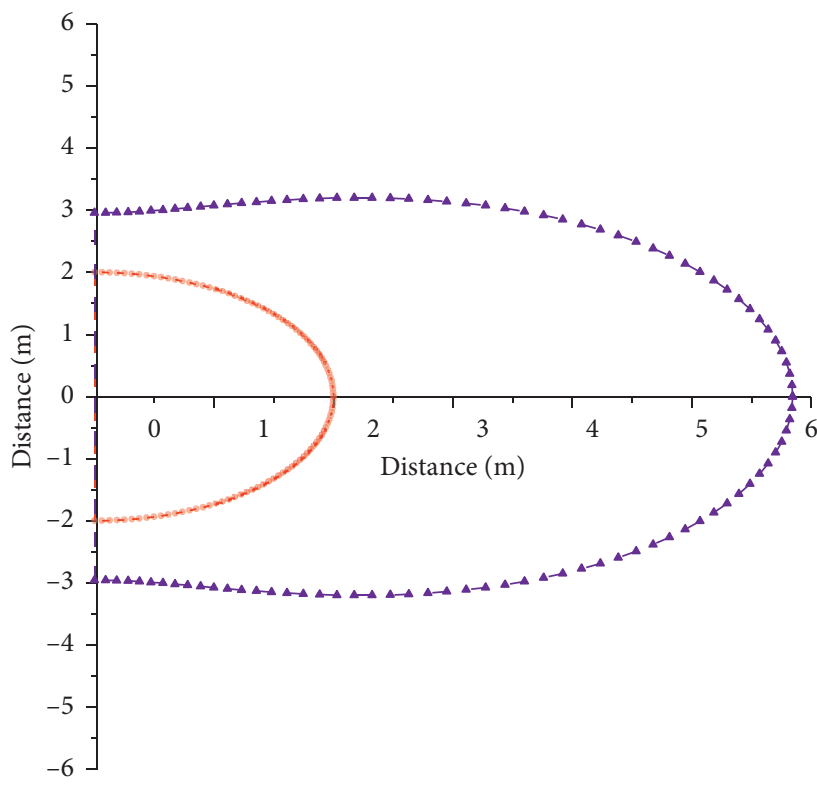

(c)

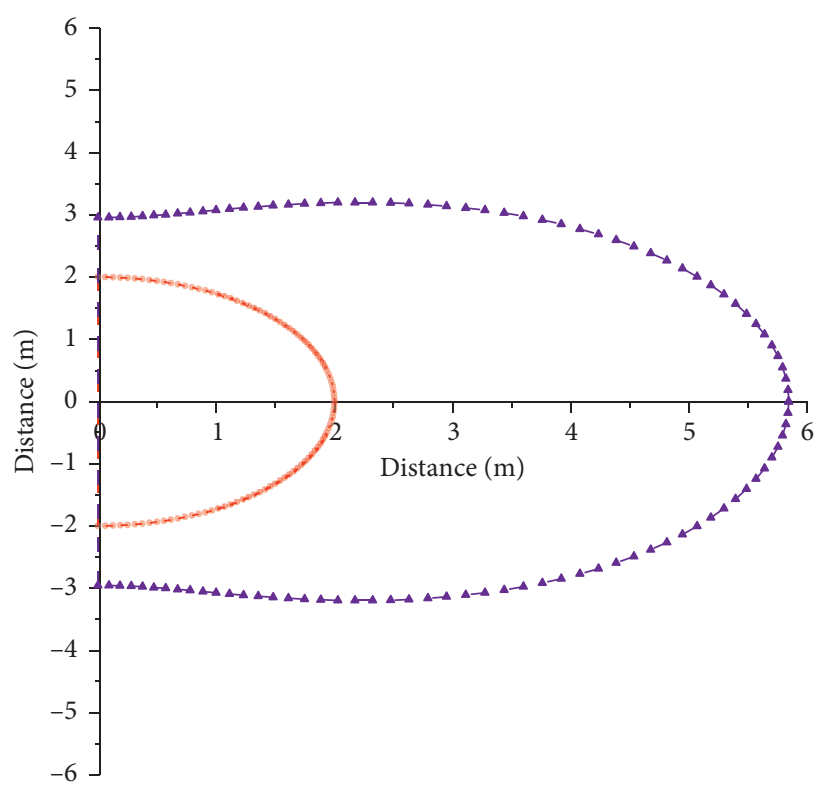

(b)

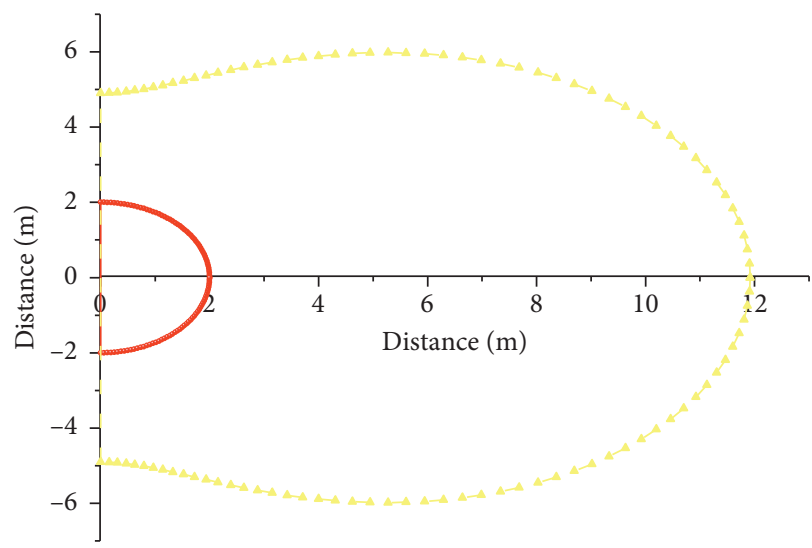

(d)

Figure 6: Relationship between original rock stress and plastic region radius. (a) Original rock stress is $10 \mathrm{MPa}$. (b) Original rock stress is $20 \mathrm{MPa}$. (c) Original rock stress is $30 \mathrm{MPa}$. (d) Original rock stress is $40 \mathrm{MPa}$.

It can be seen from Figure 7 that when the lateral pressure coefficient is 0.5 , original rock stress is $20 \mathrm{MPa}$, and all the angles of the plastic region will decrease with the increase of the internal friction angle. When original rock stress and lateral pressure coefficient remain unchanged, from the points of distribution form of the plastic region, the forms of the plastic region are irregular and present as "semidumbbell" with different internal friction angles. With the increase of the internal friction angle, the width of the plastic region tends to decrease. 


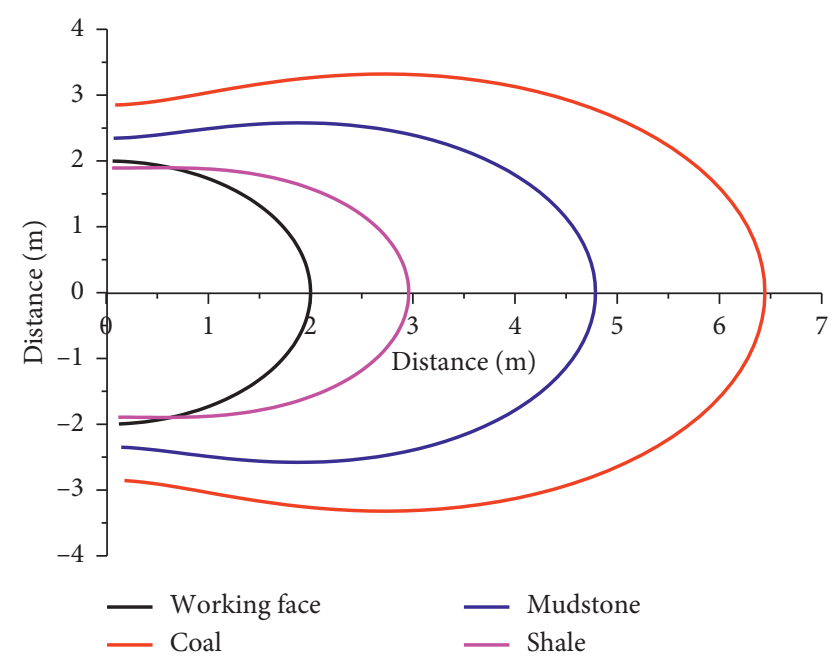

FIGURE 7: Relationship between the internal friction angle and plastic region radius.

\section{Conclusion}

Coal and gas outburst is an important disaster in the process of mining. Studying the stress transfer and instability process in coal and gas outburst will help to explore effective coal and gas outburst prediction and technical methods. We provide theoretical support for further improving coal and gas outburst monitoring and early warning technology and roadway support. This paper has used the theory of elastoplasticity mechanics to solve the stress distribution equation under equal pressure and then use Mohr's theory of failure and the boundary equation of the elasto-plastic boundary to establish mechanical models of stress distribution and width of plastic region in front of driving face under nonuniform conditions. In addition, this paper analyzes the influence of key factors on stress distribution and the width and form of plastic region, including physical and mechanical properties of coal-rock mass, original rock stress, and internal friction angle etc. the conclusions are follows:

(1) Through analysis of examples, the form features of the plastic region under different mechanical parameters have been determined, the variation range of width of the plastic region has been given, and the results show that the plastic region in front of the working face presents as "semidumbbell" without the influence of tectonic stress.

(2) Stress distribution before semicircular arch tunneling is not only related to the lithology of coal-rock mass but also related to original rock stress and internal friction angle (cohesion). Compared with coal tunnel excavation, the stress concentration effect is more obvious in front of the rock tunnel working face, the peak stress peak is the highest in front of the rock tunnel working face, and the plastic region in front of the coal tunnel working face is large. The stress concentration value of coal-rock mass increases with the increase of mining depth, internal friction, and cohesion.

(3) Without the influence of tectonic stress and with the decrease of lateral pressure coefficient, the increment of the plastic region in horizontal direction is far greater than that in the vertical direction, which makes the plastic region present as "semidumbbell." The form of the plastic region presents as "semidumbbell" with different internal friction angles, and it decreases with the increase of the internal friction angle. With the increase of gas content in coal bed, the "semidumbbell" shape of the plastic region in excavation is more obvious.

\section{Data Availability}

The data used to support the findings of this study are available from the corresponding author upon request.

\section{Conflicts of Interest}

The authors declare that there are no conflicts of interest.

\section{Acknowledgments}

The authors gratefully acknowledge the funding provided by China University of Mining and Technology (Beijing) under grant no. [2017]098.

\section{References}

[1] T. Li, C. Ma, M. Zhu, L. Meng, and G. Chen, "Geomechanical types and mechanical analyses of rockbursts," Engineering Geology, vol. 222, pp. 72-83, 2017.

[2] H. P. Kang, "Stress distribution characteristics and strata control technology for roadways in deep coal mines," Coal Science \& Technology, vol. 41, no. 9, pp. 12-17, 2013.

[3] J. Liu, E. Y. Wang, E. L. Zhao, W. Xu, and S. Hu, "Distribution and variation of mining-induced stress field in deep workface," Journal of Mining \& Safety Engineering, vol. 31, no. 1, pp. 60-65, 2014.

[4] H. W. Wang, Y. D. Jiang, T. Yang, D. Q. Zhang, and T. H. Ning, "Study on mining induced stress distribution under faults structure," Coal Engineering, vol. 48, no. 1, pp. 92-94, 2016.

[5] W. Q. Xu, "Studies on mornitoring technology of mining space surrounding rock stress and its application," $\mathrm{Ph}$ D. thesis, China University Mining and Technology, Xuzhou, China, 2012.

[6] X. Y. Zhang, Study on Width Effect on the Mechanical Characteristics of the Stope Surrounding Rock Stress Shell, Anhui University of Science \& Technology, Huainan, China, 2013.

[7] H. P. Kang, "Analysis on types and interaction of stress fields in underground coal mines," Jouranl of China Coal Society, vol. 33, no. 12, pp. 1329-1335, 2008.

[8] H. B. Luan, Z. H. Wang, D. Z. Kong, and Z. Liu, "Abutment pressure distribution characteristics in gangue filling stope with hard roof," Safety in Coal Mines, vol. 45, no. 4, pp. 204-207, 2014.

[9] X. J. Lu, Research on the Dynamic Mechanical Response of Driving Affected Region in Coal Roadway and its Effect on 
Dynamic Disaster, China University of Mining and Technology, Xuzhou, China, 2014.

[10] C. H. Xu, Study on Floor of Deformation and Damage and Floor Stress Field under Different Lithology Environments, Anhui University of Science \& Technology, Huainan, China, 2010.

[11] A. Burra, J. S. Esterle, and S. D. Golding, "Horizontal stress anisotropy and effective stress as regulator of coal seam gas zonation in the Sydney Basin, Australia," International Journal of Coal Geology, vol. 132, pp. 103-116, 2014.

[12] C. W. Li, X. Q. Zhang, C. M. Wei, and Y. Nie, "Study on plastic zone distribution characteristic of coal and rock mass in excavation from crosscut coal," Geofluids, vol. 2020, Article ID 6610399, 14 pages, 2020.

[13] M. Najafi, S. M. E. Jalali, and R. Khalokakaie, “Thermalmechanical-numerical analysis of stress distribution in the vicinity of underground coal gasification (UCG) panels," International Journal of Coal Geology, vol. 134-135, pp. 1-16, 2014.

[14] C. T. Dong, Study on Xuandong Second Mine Stope Ground Pressure Features and Working Face Gas Emission Law, China University of Mining And Technology, Xuzhou, China, 2014.

[15] Z. X. Hu and G. X. Xie, "A research of asynchronous and synchronous characteristics of coal seam gas pressure controlled by the mining-induces stress," Journal of Mining \& Safety Engineering, vol. 32, no. 6, pp. 1037-1042, 2015.

[16] H. Guo, L. Yuan, B. Shen, Q. Qu, and J. Xue, "Mining-induced strata stress changes, fractures and gas flow dynamics in multi-seam longwall mining," International Journal of Rock Mechanics and Mining Sciences, vol. 54, pp. 129-139, 2012.

[17] W. H. Somerton, I. M. Söylemezoḡlu, and R. C. Dudley, "Effect of stress on permeability of coal," International Journal of Rock Mechanics and Mining Sciences \& Geomechanics, vol. 12, no. 5-6, pp. 129-145, 1975.

[18] S. Durucan and J. S. Edwards, "The effects of stress and fracturing on permeability of coal," Mining Science and Technology, vol. 3, no. 3, pp. 205-216, 1986.

[19] D. Jasinge, P. G. Ranjith, and S. K. Choi, "Effects of effective stress changes on permeability of latrobe valley brown coal," Fuel, vol. 90, no. 3, pp. 1292-1300, 2011.

[20] I. Palmer, "Permeability changes in coal: analytical modeling," International Journal of Coal Geology, vol. 77, no. 1-2, pp. 119-126, 2009.

[21] J. Liu, Z. Chen, D. Elsworth, X. Miao, and X. Mao, "Linking gas-sorption induced changes in coal permeability to directional strains through a modulus reduction ratio," International Journal of Coal Geology, vol. 83, no. 1, pp. 21-30, 2010.

[22] H. Zhang, J. Liu, and D. Elsworth, "How sorption-induced matrix deformation affects gas flow in coal seams: a new FE model," International Journal of Rock Mechanics and Mining Sciences, vol. 45, no. 8, pp. 1226-1236, 2008.

[23] Q. X. Meng, W. Y. Xu, H. L. Wang, X. Y. Zhuang, W. C. Xie, and T. Rabczuk, "DigiSim-an open source software package for heterogeneous material modeling based on digital image processing," Advances in Engineering Software, vol. 148, Article ID 102836, 2020.

[24] Q.-X. Meng, H.-L. Wang, W.-Y. Xu, and Y.-L. Chen, "Numerical homogenization study on the effects of columnar jointed structure on the mechanical properties of rock mass," International Journal of Rock Mechanics and Mining Sciences, vol. 124, Article ID 104127, 2019.

[25] Q. X. Meng, H. L. Wang, M. Cai, W. Y. Xu, X. Y. Zhuang, and T. Rabczuk, "Three-dimensional mesoscale computational modeling of soil-rock mixtures with concave particles," Engineering Geology, vol. 277, Article ID 105802, 2020.

[26] C. Zhu, Z. Yan, Y. Lin, F. Xiong, and Z. Tao, "Design and application of a monitoring system for a deep railway foundation pit project," IEEE Access, vol. 7, pp. 107591107601, 2019.

[27] C. Zhu, Z. G. Tao, M. C. He, F. Xiong, and Z. G. Tao, "Combined application of optical fibers and CRLD bolts to monitor deformation of a pit-in-pit foundation," Advances in Civil Engineering, vol. 2019, Article ID 2572034, 16 pages, 2019.

[28] C. Zhu, X. D. Xu, X. T. Wang, F. Xiong, and J. Chen, "Experimental investigation on nonlinear flow anisotropy behavior in fracture media," Geofluids, vol. 2019, Article ID 5874849, 9 pages, 2019.

[29] Q. F. Wang, Y. C. Zhao, Y. L. Wang, D. H. Ai, and C. W. Li, "Model of stress distribution during coal roadway excavation and its numerical validation," Arabian Journal of Geosciences, vol. 13, p. 187, 2020.

[30] Y. P. Wu, M. Y. Liu, W. Y. Lv, and B. S. Hu, "Mechanical model of underground shaft coal pocket and deformation of silo wall in coal mines," Advances in Civil Engineering, vol. 2020, Article ID 8892091, 11 pages, 2020.

[31] J. Ning, J. Wang, Y. Tan, and Q. Xu, "Mechanical mechanism of overlying strata breaking and development of fractured zone during close-distance coal seam group mining," International Journal of Mining Science and Technology, vol. 30, no. 2, pp. 207-215, 2020.

[32] B. Yu and L. F. Zhang, "Study on the abutment pressure distribution in top coal caving," Arabian Journal of Geosciences, vol. 13, p. 162, 2020.

[33] Y. Wang, B. Zhang, S. H. Gao, and C. H. Li, "Investigation on the effect of freeze-thaw on fracture mode classification in marble subjected to multi-level cyclic loads," Theoretical and Applied Fracture Mechanics, vol. 111, Article ID 102847, 2021.

[34] R. C. Jiang, F. Dai, Y. Liu, and A. Li, "Fast marching method for microseismic source location in cavern-containing rockmass: performance analysis and engineering application," Engineering, vol. 4, 2021. 